\title{
Factors associated with dental fluorosis in school children in southern Brazil: a cross-sectional study
}

\section{Marina Sousa AZEVEDO(a) \\ Marília Leão GOETTEMS(a) \\ Dione Dias TORRIANI(a) \\ Flávio Fernando DEMARCO(b)}

(a) Social and Preventive Dentistry, School of Dentistry, Universidade Federal de Pelotas UFPel, Pelotas, RS, Brazil.

(b) Restorative Dentistry, School of Dentistry, Universidade Federal de Pelotas - UFPel, Pelotas, RS, Brazil.

Declaration of Interests: The authors certify that they have no commercial or associative interest that represents a conflict of interest in connection with the manuscript.

Corresponding Author:

Flávio Fernando Demarco

E-mail: ffdemarco@gmail.com

DOI: 10.1590/1807-3107BOR-2014.vol28.0014 Epub XXXXX, 2014

Submitted: Apr 29, 2013

Accepted for publication: Jan 28, 2014

Last revision: Apr 16, 2014

\begin{abstract}
This cross-sectional study assessed risk factors for dental fluorosis (DF) among 8- to 12-year-old children in southern Brazil. Children attending 20 schools were randomly selected $(n=1,196)$. They were interviewed and their parents answered a questionnaire that was sent home. Prevalence of DF was 8.53\% (modified Dean's criteria), and the prevalence of severe DF was $0.17 \%$. The results of multiple logistic regression analyses indicated that DF was associated with a higher frequency of tooth brushing and with initial use of fluoride toothpaste at the emergence of the first tooth. DF does not constitute a public health problem in southern Brazil.
\end{abstract}

Keywords: Fluorosis, Dental; Child; Epidemiology.

\section{Introduction}

The decline in global prevalence of dental caries has been largely attributed to widespread use of fluoridated toothpaste, ${ }^{1}$ to the presence of natural fluoride (F) in drinking water and to water fluoridation programs. ${ }^{2}$ Regardless of the purported benefits of fluoridation, exposure to $\mathrm{F}$ is associated with increased prevalence of dental fluorosis (DF), an irreversible condition caused by excessive ingestion of $\mathrm{F}$ during tooth development, which results in defects in the tooth enamel. ${ }^{3}$ It is known that the prevalence and severity of DF is directly related to the amount of $\mathrm{F}$ ingested, age at the time of exposure and duration of exposure. ${ }^{4}$ In contrast to the prevalence of dental caries, the prevalence of DF has increased worldwide. ${ }^{5}$

Epidemiological surveys in Brazil have found a prevalence rate ranging from $3 \%$ to $80.4 \%{ }^{4,6}$ In other countries, prevalence rates ranging from $15.8 \%{ }^{7}$ to $60.4 \%{ }^{8}$ have been reported. ${ }^{8}$ Depending on its severity, DF may not only have esthetic consequences, but may also cause fracture, loss of enamel and pain, and may also adversely affect food choices, compromise chewing efficiency, and require complex dental treatment. ${ }^{9}$

Although the sources and amounts of $\mathrm{F}$ to which children are exposed vary not only among countries but also among different regions of a country, few studies have examined the prevalence of DF among children in southern Brazil. ${ }^{10,11}$ Knowing the habits possibly associated with DF is an important factor to be considered in preventing its occurrence. Striving to fill this research gap, the present study aimed at determining the prevalence of DF among 8- to 12-year-old schoolchildren in Pelotas, a city in southern Brazil, and at assessing the associated risk factors. 


\section{Methodology}

\section{Study setting and population}

This cross-sectional study is part of a comprehensive oral health survey carried out between September and December 2010, in Pelotas, a city of 320,000 inhabitants, with a fluoridated water supply as of 1961. In Pelotas, the F concentration of the water supply is between 0.6 and $0.9 \mathrm{mgF} / \mathrm{L}$, on average. In 2010, the mean concentration was 0.67 . This research protocol was approved by the Ethics Committee of the Universidade Federal de Pelotas (UFPel), School of Dentistry (protocol no. 160/2010), and written informed consent was obtained from each parent or guardian. Dental treatment was provided to all children who required it.

In line with an estimated DF prevalence rate of $12.7 \%,{ }^{12}$ a margin of error of $3 \%$, and a confidence level of $95 \%$, it was determined that at least 612 children aged 8-12 years attending either private or public schools in the urban area of the city would have to be selected to serve as the study sample. Adoption of a cluster sample selection design led to a design effect estimated at 2 . The sample size was increased by $20 \%$ to compensate for an estimated $20 \%$ non-response rate. The minimum sample size of this study was large, because it also assessed other outcomes. For the purpose of examining the association between $\mathrm{DF}$ and the independent variables, the final sample $(n=1196)$ had $80 \%$ power to detect prevalence ratios of 1.56 as significant, with a $95 \%$ confidence interval. The sample was selected using a 2-stage cluster method. In the first stage, 20 schools ( 5 private and 15 public) were randomly selected to ensure proportionality. In the second stage, 5 classes from the $2^{\text {nd }}$ to the $6^{\text {th }}$ year were selected from each school, and the parents of the children in each class were invited to participate in the study. All children enrolled in these classes were initially eligible for the study. Physically and/or mentally disabled children were excluded from the study. A previous study has been published giving a more detailed description of the methodology used..$^{13}$

\section{Data collection}

The parents were administered a questionnaire. The level of parents' education was evaluated in terms of years of formal education, and was classi- fied into 2 groups: $<8$ and $\geq 8$ years. Family income was measured in Brazilian reais and dichotomized by median split. Parents were asked about the duration of breastfeeding, categorized as never, up to 6 months - as recommended by the World Health Organization (WHO) and over 6 months. The parents were also asked when they began brushing their children's teeth with F dentifrice, and were divided into 2 categories, depending on their response, i.e., they began either when the child reached an age of up to 12 months or when the first tooth erupted, or else when the child reached 12 months or more.

The children were interviewed to collect demographic information (gender and age) and frequency of tooth brushing, categorized as once a day or less, or as twice a day or more. The children's skin color was determined by the examiner as white or non-white. The type of school was classified as public or private.

Oral clinical examinations were performed at the school by 6 dentists using a modified Dean's criteria: $0=$ no or questionable, $1=$ very mild, $2=$ mild, $3=$ moderate, and $4=$ severe DF. The individual-level score was determined using the scores of the 2 teeth that received the worst scores, and the presence of DF was differentiated from that of other opacities. ${ }^{14}$ Clinical oral examiners were not aware of the children's responses during their interview to avoid bias during examination.

The examiners participated in a training session, followed by a calibration exercise, before the data were collected, to ensure reliability. Because of the low DF prevalence, calibration was performed in lux , consisting of the projection of 30 photographic images. The interexaminer reliability of the calibration was assessed by the Kappa test, comparing the results of the examiners with the gold standard for image records. Interexaminer unweighted Kappa values ranged from 0.81 to 0.89 for $\mathrm{DF}$.

\section{Statistical analysis}

The data were analyzed using Stata software version 10.0 (Stata Corporation, College Station, USA). Descriptive analysis was performed. Fisher exact test and chi-square test were used to test the association between DF severity and the independent variables. Bivariate and multiple logistic regression 
analyses were conducted using a forward stepwise procedure, to assess factors associated with the presence or absence of DF. The criterion for inclusion of the independent variables in the model was set at 0.20 . Values of $p<0.05$ were considered significant.

\section{Results}

Of the 1,744 children invited to participate in this study, 1,325 (76.0\%) returned the questionnaire and informed consent form. Data from 114 (8.6\%) chil- dren were lost during data collection, because of their absence from school. Of the remaining 1,211 children, 1,196 were examined for DF - 15 could not be examined because they had extensive carious lesions or were wearing orthodontic appliances that hindered examination. Table 1 shows the sample distribution according to DF severity.

Table 2 shows the results of the bivariate and multivariate analyses. The bivariate analysis indicated that the children who had a higher prevalence of DF

Table 1. Sample distribution according to fluorosis severity among 8 - to 12-year-old children and independent variables. Pelotas/2010 ( $\mathrm{n}=1,196)$.

\begin{tabular}{|c|c|c|c|c|c|}
\hline Variable & Total & Very mild n (\%) & Mild n (\%) & Moderate/severe n (\%) & $p$-value* \\
\hline Gender & & & & & $0.094^{*}$ \\
\hline Male & 568 & $18(3.17)$ & $21(3.70)$ & $5(0.88)$ & \\
\hline Female & 628 & $27(4.30)$ & $16(2.55)$ & 15 (2.39) & \\
\hline Age (years) & & & & & $0.721^{*}$ \\
\hline 8 & 179 & $6(3.35)$ & $3(1.68)$ & $2(1.12)$ & \\
\hline 9 & 308 & $9(2.92)$ & $10(3.25)$ & $5(1.62)$ & \\
\hline 10 & 294 & $9(3.06)$ & $13(4.42)$ & $4(1.36)$ & \\
\hline 11 & 255 & $15(5.88)$ & $7(2.75)$ & $6(2.35)$ & \\
\hline 12 & 160 & $6(13.75)$ & $4(2.50)$ & $3(1.88)$ & \\
\hline Skin color & & & & & $0.721^{* *}$ \\
\hline White & 847 & $32(3.78)$ & $30(3.54)$ & $14(1.65)$ & \\
\hline Non-white & 313 & $13(4.15)$ & $7(2.24)$ & $19(1.64)$ & \\
\hline Type of school & & & & & $0.040^{*}$ \\
\hline Private & 248 & $16(6.45)$ & $11(4.44)$ & $4(1.61)$ & \\
\hline Public & 948 & $29(3.06)$ & $26(2.74)$ & $16(1.69)$ & \\
\hline Mother's schooling & & & & & $0.783^{* *}$ \\
\hline$\geq 8$ years & 744 & $26(3.49)$ & $25(3.36)$ & $12(1.61)$ & \\
\hline$<8$ years & 417 & $17(4.08)$ & $10(2.40)$ & $7(1.68)$ & \\
\hline Family income (BRL) & & & & & $0.916^{* *}$ \\
\hline$>730.00 \mathrm{R} \$$ & 512 & $20(3.91)$ & $17(3.32)$ & $8(1.56)$ & \\
\hline$\leq 730.00 \mathrm{R} \$$ & 515 & $17(3.30)$ & $15(2.91)$ & $7(1.36)$ & \\
\hline Tooth brushing begins & & & & & $<0.001^{* *}$ \\
\hline$>12$ months & 743 & $23(3.10)$ & $11(1.48)$ & $10(1.35)$ & \\
\hline$\leq 12$ months & 414 & $21(5.07)$ & $24(5.80)$ & $8(1.93)$ & \\
\hline Breastfeeding & & & & & $0.457^{*}$ \\
\hline$>6$ months & 496 & 19 (3.83) & $12(2.42)$ & $9(1.81)$ & \\
\hline$\leq 6$ months & 546 & $19(3.48)$ & $22(4.03)$ & $7(1.28)$ & \\
\hline Never & 109 & $3(2.75)$ & $1(0.92)$ & $3(2.75)$ & \\
\hline Tooth brushing frequency & & & & & $<0.001^{*}$ \\
\hline Twice/day or less & 480 & $14(2.92)$ & $5(1.04)$ & $4(0.83)$ & \\
\hline Three times/d or more & 690 & $31(4.49)$ & $32(4.64)$ & $16(2.32)$ & \\
\hline Total & 1196 & $45(3.76)$ & 37 (3.09) & $20(1.67)$ & \\
\hline
\end{tabular}

*Fisher exact test; ${ }^{* *}$ Chi-square test. 
- Factors associated with dental fluorosis in school children in southern Brazil: a cross-sectional study

Table 2. Unadjusted and adjusted logistic regression models for prevalence of dental fluorosis among 8- to 12-year-old children. Pelotas/2010 ( $n=1,196)$.

\begin{tabular}{|c|c|c|c|c|c|c|}
\hline \multirow[t]{2}{*}{ Variable } & \multicolumn{2}{|c|}{ Dental fluorosis } & \multirow[t]{2}{*}{$\mathrm{OR}^{\mathrm{c}}(95 \% \mathrm{Cl})$} & \multirow[t]{2}{*}{$p$-value } & \multirow[t]{2}{*}{$\mathrm{OR}^{\mathrm{a}}(95 \% \mathrm{Cl})$} & \multirow[t]{2}{*}{$p$-value } \\
\hline & $n$ & $\%$ & & & & \\
\hline Gender & & & & 0.358 & & \\
\hline Male & 44 & 7.75 & 1.00 & & & \\
\hline Female & 58 & 9.24 & $1.21(0.80-1.82)$ & & & \\
\hline Age (years) & & & & 0.198 & & 0.082 \\
\hline 8 & 11 & 6.15 & 1.00 & & 1.00 & \\
\hline 9 & 24 & 7.79 & $1.29(0.62-2.70)$ & & $1.21(0.55-2.66)$ & \\
\hline 10 & 26 & 8.84 & $1.48(0.71-3.08)$ & & $1.58(0.73-3.43)$ & \\
\hline 11 & 28 & 10.98 & $1.88(0.91-3.89)$ & & $2.08(0.97-4.47)$ & \\
\hline 12 & 13 & 8.13 & $1.35(0.59-3.11)$ & & $1.51(0.62-3.69)$ & \\
\hline Skin color & & & & 0.597 & & \\
\hline White & 76 & 8.97 & 1.00 & & & \\
\hline Non-white & 25 & 7.99 & $0.88(0.55-1.41)$ & & & \\
\hline Type of school & & & & 0.013 & & 0.065 \\
\hline Private & 31 & 12.5 & 1.00 & & 1.00 & \\
\hline Public & 71 & 7.49 & $0.57(0.36-0.89)$ & & $0.63(0.39-1.03)$ & \\
\hline Mother's schooling & & & & 0.853 & & \\
\hline$\geq 8$ years & 51 & 8.25 & 1.00 & & & \\
\hline$<8$ years & 46 & 8.47 & $0.96(0.62-1.48)$ & & & \\
\hline Family income (BRL) & & & & 0.378 & & \\
\hline$>730.00 \mathrm{R} \$$ & 45 & 8.79 & 1.00 & & & \\
\hline$\leq 730.00 \mathrm{R} \$$ & 39 & 7.57 & $0.82(0.52-1.28)$ & & & \\
\hline Tooth brushing begins & & & & $<0.001$ & & 0.001 \\
\hline$>12$ months & 44 & 5.92 & 1.00 & & 1.00 & \\
\hline$\leq 12$ months & 53 & 12.8 & $2.33(1.53-3.55)$ & & $2.05(1.33-3.16)$ & \\
\hline Breastfeeding & & & & 0.860 & & \\
\hline$>6$ months & 40 & 8.06 & 1.00 & & & \\
\hline$\leq 6$ months & 48 & 8.79 & $1.10(0.71-1.70)$ & & & \\
\hline Never & 7 & 6.42 & $0.78(0.34-1.80)$ & & & \\
\hline Tooth brushing frequency & & & & $<0.001$ & & $<0.001$ \\
\hline Twice/day or less & 23 & 4.79 & 1.00 & & 1.00 & \\
\hline Three times/d or more & 79 & 11.45 & $2.57(1.59-4.15)$ & & $2.55(1.55-4.22)$ & \\
\hline
\end{tabular}

${ }^{c}$ crude; ${ }^{a}$ adjusted for age, type of school, start and frequency of tooth brushing; 1 Brazilian Real (BRL) $=0.49$ USD.

were those who engaged in a relatively higher frequency of tooth brushing, attended a private school, and began using $\mathrm{F}$ toothpaste when their first primary tooth emerged or at an age of up to 12 months. After the variables were adjusted, it was found that the children who began using fluoride toothpaste at an age up to 12 months or when the first tooth erupted had a 2.05-time greater risk of having DF than children who began using fluoride toothpaste later. In addition, children who brushed their teeth more than twice a day had a 2.55-time greater risk of having DF than children who brushed their teeth twice a day or less.

\section{Discussion}

In the present study, $8.53 \%$ of the sample showed clinical signs of DF. This finding was consistent with that found in previous studies. ${ }^{15,16}$ However, only $0.17 \%$ of the children were found to have severe DF. This was expected, since very mild and mild forms are 
more common in areas of optimal fluoride content in drinking water, as is the case of Pelotas ( $0.67 \mathrm{ppm}$ F). Steiner et al. ${ }^{17}$ detected that most children with DF presented less severe forms of opacities, and concluded that fluoride-associated enamel opacities are not a cosmetic problem and certainly not a public health concern. In a study that assessed the perception of DF as an oral health problem among 12-yearold Brazilian children, Meneghim et al. ${ }^{18}$ found that the children examined did not have a negative perception of DF, except when it reached severe levels.

The present study investigated a series of demographic, socioeconomic, and behavioral variables possibly associated with DF. Gender and age were not associated with DF. Although several studies have found that the female sex was associated with $\mathrm{DF}^{6,19}$ these results are controversial. ${ }^{20}$ Although there is no consensus in the literature regarding an association between DF and socioeconomic factors, authors have suggested a relationship between higher socioeconomic status and increased access to fluoridated products. On the other hand, it has been speculated that children from low-income families are at greater risk of exposure to higher $\mathrm{F}$ doses. This could be related to the fact that the higher amounts of dentifrice dispensed to these children have been associated with lower socioeconomic status and parental education level. Although children from higher socioeconomic status tend to use children's toothpaste, instead of the family dentifrice, the amount of dentifrice used can strongly increase the risk of exposure to higher doses of $\mathrm{F}$, regardless of the type of dentifrice. ${ }^{21}$ Maltz and Silva ${ }^{10}$ found that children who attended private schools had a higher prevalence of DF, but found no direct association between either family income or parental schooling. Similarly, other authors have found no association between DF and socioeconomic indicators. ${ }^{18,19}$

Use of $\mathrm{F}$ toothpaste has been identified as a potential risk factor for DF, particularly because an inverse relationship has been observed between age and mean ingestion of toothpaste. ${ }^{22}$ Both the frequency of tooth brushing and the age at which tooth brushing began were found to be associated with DF in the present study. It has been reported that an early age of tooth brushing initiation is associated with higher TFI mean scores. The authors of the abovementioned finding ${ }^{22}$ presumed this was connected to the lack of supervision in young children to advise them to spit out toothpaste rather than swallow it. ${ }^{23}$ Since most commercial brands of toothpaste on the Brazilian market are fluoridated, they serve as important sources of $\mathrm{F}$, but present substantial risk associated with ingestion by children. It has been shown that not all ingested F from toothpaste will be absorbed, and may not be absorbed systemically. ${ }^{21,24}$ The finding that children who initiated tooth brushing at an early age had a higher prevalence of DF may suggest that they swallowed a quantity of fluoridated toothpaste great enough to have had a negative systemic impact.

Different strategies to address this issue are recommended, among which is the use of low F toothpaste by young children. However, a systematic review verified that low $\mathrm{F}$ toothpaste significantly increased the risk of caries in primary dentition and did not significantly decrease the risk of fluorosisrelated esthetic consequences to the upper anterior permanent teeth; therefore, there is no evidence to support the use of low $\mathrm{F}$ toothpastes. ${ }^{25}$

A systematic review, combining data from 4 studies, showed a reduction in the risk of DF if children brushed their teeth/had their teeth brushed after 12 to 14 months of age. However, the evidence was not considered very substantial, since there were no randomized controlled trials assessing this relationship. ${ }^{26}$ Furthermore, a study estimating $F$ intake either from diet, or dentifrice or a combination of both for children with and without DF, found a similar F intake for both groups of children. ${ }^{27}$

An association between a higher frequency of tooth brushing and fluorosis was detected in this study, in agreement with other studies. ${ }^{20,28}$ Although the frequency of tooth brushing was not precise, it was used as a proxy measurement for the amount of F toothpaste being ingested, ${ }^{26}$ insofar as higher frequencies of tooth brushing are expected to increase the risk of $\mathrm{F}$ intake. ${ }^{21}$ Although other proxy measurements have been suggested, including those of collecting information on whether the child liked, swallowed or ate dentifrices, this study only assessed the current tooth brushing practices of the sample. ${ }^{26} \mathrm{It}$ is possible that these children engaged in more frequent tooth brushing ever since they began brushing 
their teeth. This possibility is supported by Pendrys et al. ${ }^{29}$ who found that $34 \%$ of the cases of DF could be explained by initiation of tooth brushing more often than once a day and brushing with $\mathrm{F}$ toothpaste at an age under 2 years of age. On the other hand, Wong et al. ${ }^{26}$ performed a meta-analysis of four cross-sectional surveys and found no significant association between frequency of tooth brushing and DF. The findings of this study suggest that advising parents of the proper use of $\mathrm{F}$ dentifrices by their children and urging them to supervise their children during tooth brushing are recommendations widely accepted by dentists, and add to the benefits of reducing the risk of DF. Each parent should be well informed about the many benefits and little damage associated with brushing their children's teeth with F toothpaste.

A prolonged period of breastfeeding has been associated with the prevention of fluorosis. ${ }^{30}$ This could be attributed to the fact that human milk has a very low $\mathrm{F}$ content, and that children fed exclusively with human milk are not exposed to fluoridated water, whereas those fed with powdered concentrate mixed with water as their main source of nutrition are exposed. The association between duration of breastfeeding and fluorosis was not detected in this

\section{References}

1. Cury JA, Tenuta LMA, Ribeiro CCC, Paes Leme AF. The importance of fluoride dentifrices to the current dental caries prevalence in Brazil. Braz Dent J. 2004 Sep-Dec;15(3):167-74.

2. Smith RS. World Water Day 2001: oral health [Internet]. Geneve: World Health Organization; 2008 [cited 2013 Jan 17]. Available from: http://www.who.int/water_sanitation_ health/oralhealth/en/print.html.

3. CDC. Centers for disease control and prevention. Ten Great Public Health Achievements - United States, 1900-1999; [cited 2013 Mar 11]. Available from:http://www.cdc.gov/about/ history/tengpha.htm

4. Ferreira EF, Vargas AM, Castilho LS, Velásquez LN, Fantinel LM, Abreu MH. Factors associated to endemic dental fluorosis in Brazilian rural communities. Int J Environ Res Public Health. 2010 Aug;7(8):3115-28.

5. Moysés SJ, Moysés ST, Allegretti AC, Argenta M, Werneck R. Dental fluorosis: epidemiological fiction? Rev Panam Salud Publica. 2002 Nov;12(5):339-46. Portuguese.

6. Bardal PAP, Olympio KPK, Buzalaf MAR, Bastos JRM. Dental caries and dental fluorosis in 7-12-year-old schoolchildren in Catalão, Goiás, Brazil. J Appl Oral Sci. 2005 Mar;13(1):35-40. study. Inferences about this association could not be made, since data on early feeding practices, such as consumption of infant formula, was not collected.

One of the limitations of this study was its use of a cross-sectional design, which limited the extent to which causal inferences could be made. Another limitation was the possibility of recall bias, since mothers were requested to answer questions regarding their children's exposure to F during early childhood. Among the several epidemiological indices that have been proposed for describing the clinical appearance of DF, Dean's Fluorosis Index was selected because of its simplicity and the availability of related data. In terms of external validity, the number of schools included, the sampling method employed and the good response rate assured representativeness of the children enrolled in the city's schools.

\section{Conclusions}

Dental fluorosis does not constitute a major public health problem of broad dimensions in southern Brazil. Considering the limitation of this study's cross-sectional design, the findings report that dental fluorosis in this sample was associated with tooth brushing habits.

7. Baskaradoss JK, Clement RB, Narayanan A. Prevalence of dental fluorosis and associated risk factors in 11-15 year old school children of Kanyakumari District, Tamilnadu, India: a cross sectional survey. Indian J Dent Res. 2008 Oct-Dec;19(4):297-303.

8. Juárez-López ML, Hernández-Guerrero JC, Jiménez-Farfán D, Ledesma-Montes C. Prevalence of dental fluorosis and caries in Mexico city schoolchildren. Gac Med Mex. 2003 May-Jun;139(3):221-5. Spanish.

9. National Research Council. Fluoride in drinking water: a scientific review of EPA's standards. Washington, DC: The National Academies Press, 2006. 530 p.

10. Maltz M, Silva BB. Relationship among caries, gingivitis and fluorosis and socioeconomic status of school children. Rev Saude Publica. 2001 Apr;35(2):170-6. Portuguese.

11. Peres KG, Latorre MRDO, Peres MA, Traebert J, Panizzi M. Impact of dental caries and dental fluorosis on 12-year-old schoolchildren's self-perception of appearance and chewing. Cad Saude Publica. 2003 Jan-Feb;19(1):323-30. Portuguese. 
12. Cypriano S, Pecharki GD, Sousa MLR, Wada RS. Oral health of schoolchildren residing in areas with or without water fluoridation in Sorocaba, São Paulo State, Brazil. Cad Saude Publica. 2003 Jul-Aug;19(4):1063-71. Portuguese.

13. Goettems ML, Correa MB, Vargas-Ferreira F, Torriani DD, Marques M, Domingues MR, et al. Methods and logistics of a multidisciplinary survey of schoolchildren from Pelotas, in the Southern Region of Brazil. Cad Saude Publica. 2013 May;29(5):867-78.

14. World Health Organization. Oral Health Survey - Basics Methods. 4th ed. Geneva: World Health Organization; 1997. 51 p.

15. Freire MCM, Reis SCGB, Gonçalves MM, Balbo PL, Leles CR. Condição de saúde bucal em escolares de 12 anos de escolas públicas e privadas de Goiânia, Brasil. Rev Panam Salud Publica. 2010;28(2):86-91.

16. Carvalho RWF, Valois RBV, Santos CNA, Marcellini PS, Bonjardim LR, Oliveira CCC, et al. Study of the prevalence of dental fluorosis in Aracaju. Cien Saude Colet. 2010 Jun;15 Suppl 1:1875-80. Portuguese.

17. Steiner M, Menghini G, Thomet E, Jäger A, Pfister J, Imfeld T. Assessment of dental fluorosis prevalence in Swiss populations. Schweiz Monatsschr Zahnmed. 2010;120(1):12-20.

18. Meneghim MC, Kozlowski FC, Pereira AC, Assaf AV, Tagliaferro EP. Perception of dental fluorosis and other oral health disorders by 12-year-old Brazilian children. Int J Paediatr Dent. 2007 May;17(3):205-10.

19. Rigo L, Caldas Junior AF, Souza EHA. Factors associated with dental fluorosis. Rev Odonto Cienc. 2010 Jan;25(1):8-14.

20. Vallejos-Sánchez AA, Medina-Solís CE, Casanova-Rosado JF, Maupomé G, Minaya-Sánchez M, Pérez-Olivares S. Dental fluorosis in cohorts born before, during, and after the national salt fluoridation program in a community in Mexico. Acta Odontol Scand. 2006 Aug;64(4):209-13.
21. Martins CC, Oliveira MJ, Pordeus IA, Cury JA, Paiva SM. Association between socioeconomic factors and the choice of dentifrice and fluoride intake by children. Int J Environ Res Public Health. 2011 Nov;8(11):4284-99.

22. Buzalaf MAR. Fluoride and the oral environment: Monogr Oral Sci. Basel: Karger; 2011. 178 p.

23. Maupomé G, Shulman JD, Clark DC, Levy SM. Socio-demographic features and fluoride technologies contributing to higher fluorosis scores in permanent teeth of Canadian children. Caries Res. 2003 Sep-Oct;37(5):327-34.

24. Falcão A, Tenuta LMA, Cury JA. Fluoride gastrointestinal absorption from Na2FPO3/CaCO3- and NaF/SiO2-based toothpastes. Caries Res. 2013 Apr;47(3):226-33.

25. Santos AP, Oliveira BH, Nadanovsky P. Effects of low and standard fluoride toothpastes on caries and fluorosis: systematic review and meta-analysis. Caries Res. 2013 Apr;47(5):382-90.

26. Wong MC, Glenny AM, Tsang BW, Lo EC, Worthington HV, Marinho VC. Topical fluoride as a cause of dental fluorosis in children. Cochrane Database Syst Rev. 2010 Jan 20;(1):CD007693.

27. Martins CC, Paiva SM, Lima-Arsati YB, Ramos-Jorge ML, Cury JA. Prospective study of the association between fluoride intake and dental fluorosis in permanent teeth. Caries Res. 2008 Apr;42(2):125-33.

28. Pendrys DG, Katz RV, Morse DE. Risk factors for enamel fluorosis in a fluoridated population. Am J Epidemiol. 1994 Sep;140(5):461-71.

29. Pendrys DG, Haugejorden O, Bårdsen A, Wang NJ, Gustavsen $F$. The risk of enamel fluorosis and caries among Norwegian children: implications for Norway and the United States. J Am Dent Assoc. 2010 Apr;141(4):401-14.

30. Wondwossen F, Astrøm AN, Bjorvatn K, Bårdsen A. Sociodemographic and behavioural correlates of severe dental fluorosis. Int J Paediatr Dent. 2006 Mar;16(2):95-103. 